\title{
Commentary on "Occupational Noise, Smoking and a High Body Mass Index are Risk Factors for Age-Related Hearing Impairment and Moderate Alcohol Consumption is Protective: a European Population-Based Multicentre Study" by Fransen et al., J. Assoc. Res. Otolaryngol. DOI 10.1007/s10162-008-0123-1
}

\author{
Marci M. Lesperance ${ }^{1}$ and Margit Burmeister ${ }^{2,3,4}$ \\ ${ }^{1}$ Division of Pediatric Otolaryngology, Department of Otolaryngology and Head and Neck Surgery, University of Michigan \\ Health System, Ann Arbor, MI, USA \\ ${ }^{2}$ Molecular \& Behavioral Neuroscience Institute, University of Michigan Health System, Ann Arbor, MI, USA \\ ${ }^{3}$ Department of Psychiatry, University of Michigan Health System, Ann Arbor, MI, USA \\ ${ }^{4}$ Department of Human Genetics, University of Michigan Health System, Ann Arbor, MI, USA
}

Received: 30 April 2008; Accepted: 2 May 2008; Online publication: 10 June 2008

\section{INTRODUCTION}

The earliest observation of high-frequency sensorineural hearing loss with aging (presbycusis) was recorded over 100 years ago (Zwaardemaker 1899). The causes of such hearing loss may be diverse: as noted by Schuknecht (1955), there is "difficulty in distinguishing the normal changes of aging from alteration caused by injury or disease." Hearing impairment is the most common sensory disorder reported in older individuals. In the U.S. population, the incidence rises from about $20 \%$ for ages $45-64$ years, to $30 \%$ for ages 65-74 years, to about $50 \%$ for ages 75 years and older (Pleis and Lethbridge-Çejku 2006). An average increase in hearing thresholds of $1 \mathrm{~dB}$ per year in those aged 60 years and older has been reported (Lee et al. 2005). Although such slow decline may appear inconsequential, the decrease in sensitivity occurs on the logarithmic scale and thus substantially degrades communication abilities. Although recent efforts have focused on genetic sources of susceptibility to hearing

Correspondence to: Marci M. Lesperance - Division of Pediatric Otolaryngology, Department of Otolaryngology and Head and Neck Surgery - University of Michigan Health System - Ann Arbor, MI, USA. Telephone: 734-936-9816; fax: 734-763-7802; email: lesperan@ med.umich.edu loss (see below), a new multicenter study of Europeans in their 50s and 60s (Fransen et al. 2008) has begun to illuminate the influence of lifestyle choices on agerelated hearing impairment. Remarkably, smoking and a high body mass index (BMI) both acted as risk factors, and moderate alcohol consumption had a modest protective effect.

The study by Fransen et al. is notable for its breadth, in terms of subject number, locale, and phenotype. Investigators at nine clinical centers in seven countries interviewed over 4,000 subjects. The investigators used a broad definition of age-related hearing loss: participants had hearing loss from a variety of etiologies, excluding only certain diseases known to affect hearing. Subjects with histories of noise and other exposures were not excluded. An additional noteworthy feature was an emphasis on subjects younger (ages 53-67 years old) than those of previous studies, in which subjects were in the seventh, eighth and even ninth decades of life. By limiting a study to early onset of a disorder, investigators hope to enrich the population for genetic susceptibility and to reduce sporadic cases or the influence of environmental causes. Somewhat surprisingly, the use by Fransen et al. of this approach may have improved their ability to isolate lifestyle factors as well. 
Smoking, BMI and alcohol consumption are known to affect cardiovascular disease, stroke, diabetes, hypertension and cancer, and associations with hearing loss have also been previously reported (Cruickshanks et al. 1998). A particularly influential previous study - the Framingham study (Gates et al. 1993) - did not find effects of smoking independent of cardiovascular disease. It has been speculated that cardiovascular disease leads to hearing loss through a reduction in cochlear blood flow or impairment of cochlear microcirculation (Torre et al. 2005). The current study by Fransen and coworkers finds instead that effects of smoking and body mass index persist even when the history of cardiovascular disease is taken into account. The different findings may reflect important differences in the studies' populations. The Framingham study involved an older, smaller group of Americans, with a higher incidence of cardiovascular disease and lower incidence of smoking (14\% vs. $47 \%$ ). Cardiovascular disease occurring in the participants of the European study was by definition mild or early in nature, as potential subjects with a history of multiple hospitalizations were excluded. The much larger number of smokers in the Fransen study may have simply provided the statistical power needed to detect associations independent of cardiovascular disease and to confirm a dosage effect.

It is important to realize that association does not imply cause and effect. Smoking in particular may be a marker for unmeasured socioeconomic, social or educational factors. In Western Europe and the United States, smoking rates for men and women are inversely correlated with wealth and educational status (Giskes et al. 2005; Gilman et al. 2003), but this is not true worldwide. Smoking trends may follow an epidemic model (Graham 1996), and smoking rates vary between men and women, and among countries, by epidemic stage. For example, a study in China found that in men, smoking is positively associated with education level (Yu et al. 2000). Smoking is less common among women in China than in Western women, a difference which has been attributed to societal disapproval (Dong et al. 2007). Fransen and colleagues did not specifically assess socioeconomic status, but their detailed data on the incidence and quantity of smoking among this specific age group in European countries are likely to be of interest from a social science perspective as well.

Noise exposure is a lifestyle factor that does have a causal effect on hearing loss. The study by Fransen et al. confirmed previous reports showing the importance of noise exposure in producing age-related hearing loss, and was further able to separately analyze the effects of recreational exposure (hunting, personal MP3 players, etc.) and occupational exposure (industrial or military in origin). The most significant result was a correlation between high-frequency hearing loss and exposure to a noisy work environment for more than 1 year.

How can the new risk information provided by this study be used to help patients? Risk communication is a fascinating area of study which is only beginning to be applied to health outcomes (Edwards et al. 2001). The influence that risk information has on patient behavior depends greatly on the manner in which the information is presented (Edwards et al. 2001; Rothman and Kiviniemi 1999). Simple provision of risk information is largely ineffective, as patients will conceptualize their personal risks on their own terms, according to their existing beliefs (Kreuter and Strecher 1996). While primary care for adults routinely includes assessment of cardiovascular disease, hearing loss is both underdiagnosed and undertreated; the identified associations between hearing loss and lifestyle factors provide an opportunity for practitioners to discuss hearing loss while addressing those same lifestyle factors in terms of other diseases. Still, the cost of hearing loss may prove more difficult to communicate: its effects are not measured by hospitalizations or surgical procedures, but by the more subtle yet substantial psychosocial costs of impaired communication (Yueh et al. 2003). A smoker who quits will have a risk of heart disease approaching his age-matched nonsmoking peers after 10-20 years. A person of high BMI who loses weight may see immediate benefit in control of multiple serious conditions, including diabetes, heart disease, arthritis, and obstructive sleep apnea. But quitting smoking or losing weight may, at best, slow the deterioration of hearing. Nevertheless, the very permanence of sensorineural hearing loss should motivate health care providers to communicate this risk.

A recent emphasis in the scientific and popular media on genetic influences on disease risk may have had the unintended effect of pushing environmental influences out of the limelight. Because the potential for genetic and environmental interactions is poorly understood by the public, patients may misuse genetic risk information to justify high-risk behavior, as in "I can smoke because I am genetically protected.” Since 1992, when the first non-syndromic deafness locus was mapped (Leon et al. 1992), hundreds of genetic loci have been implicated in hearing loss, and over 60 of the responsible genes have been identified (Van Camp and Smith 2008). Some of this work has begun to elucidate genetic factors underlying presbycusis; in related work on the same European study population, Van Laer et al. (2008) identified an association between age-related hearing loss and a single nucleotide polymorphism in a transcription factor that is expressed in the developing cochlea. Thus, the European study has revealed associations between age-related hearing loss and both a gene (Van Laer et al. 2008) and modifiable lifestyle factors (Fransen et 
al. 2008). Even larger and more complex studies, however, will be necessary to uncover gene-environment interactions and to quantify the associated risks.

\section{REFERENCES}

Cruickshanks KJ, Klein R, Klein BEK, Wiley TL, Nondahl DM, Tweed TS. Cigarette smoking and hearing loss: the epidemiology of hearing loss study. JAMA. 279(21):1715-1719, 1998.

Dong G-H, CaO Y, Ding H-L, Ma Y-N, Jin J, Zhao Y-D, He Q-C. Effects of environmental tobacco smoke on respiratory health of boys and girls from kindergarten: results from 15 districts of northern China. Indoor Air. 17:475-483, 2007.

Edwards A, Elwyn G, Covey J, Matthews E, Pill R. Presenting risk information - a review of the effects of "framing" and other manipulations on patient outcomes. J Health Communication. 6:61-82, 2001.

Fransen E, Topsakal V, Hendrickx JJ, Van Laer L, Huyghe JR, Van Eyken E, Lemkens N, Hannula S, Mäki-Torkko E, Jensen M, Demeester K, Tropitzsch A, Bonaconsa A, Mazzoli M, Espeso A, Verbruggen K, Huyghe J, Huygen PlM, Kunst S, Manninen M, Diaz-Lacava A, Steffens M, Wienker TF, Pyykkö I, Cremers CWRJ, Kremer H, Dhooge I, Stephens D, Orzan E, Pfister M, Bille M, Parving A, Sorri M, Van De Heyning P, Van Camp G. Occupational noise, smoking, and a high body mass index are risk factors for age-related hearing impairment and moderate alcohol consumption is protective: a European population-based multicenter study. J. Assoc. Res. Otolaryngol. 2008. (in press). DOI 10.1007/s10162-008-0123-1.

Gates GA, Cobb JL, D'Agostino RB, Wolf PA. The relation of hearing in the elderly to the presence of cardiovascular disease and cardiovascular risk factors. Arch. Otolaryngol. Head Neck Surg. 119:156-161, 1993.

Gilman SE, Abrams DB, Buka SL. Socioeconomic status over the life course and stages of cigarette use: initiation, regular use, and cessation. J. Epidemiol. Community Health. 57:802-808, 2003.

Giskes K, Kunst AE, Benach J, Borrell C, Costa G, Dahl E, Dalstra jaA, Federico B, Helmert U, Judge K, Lahelma E, Moussa K,
Ostergren PO, Platt S, Prattala R, Rasmussen NK, Mackenbach JP. Trends in smoking behaviour between 1985 and 2000 in nine European countries by education. J. Epidemiol. Community Health. 59:395-401, 2005.

GRAHAM H. Smoking prevalence among women in the European Community 1950-1990. Soc. Sci. Med. 43:243-254, 1996.

Kreuter MW, Strecher VJ. Do tailored behavior change messages enhance the effectiveness of health risk appraisal? Results from a randomized trial. Health Education Res. 11(1):97-105, 1996.

Lee FS, Matthews LJ, Dubno JR, Mills JH. Longitudinal study of puretone thresholds in older persons. Ear Hear. 26(1):1-11, 2005.

Leon PE, Raventos H, Linch E, Morrow J, King MC. The gene for an inherited form of deafness maps to chromosome 5q31. Proc. Natl. Acad. Sci. U S A. 89(11):5181-5184, 1992.

Pleis JR, Lethbridge-Çejku M. Summary health statistics for U.S. adults: National health interview survey, 2005. National Center for Health Statistics. Vital Health Stat. 10(232), 2006.

Rothman AJ, Kiviniemi MT. Treating people with information: an analysis and review of approaches to communicating health risk information. J. Natl. Cancer Inst. Monogr. 25:44-51, 1999.

Schuknecht HF. Presbycusis. Trans. Am. Laryngol. Rhinol. Otol. Soc. (59th Meeting):401-418, 1955.

Torre P, Cruickshanks KJ, Klein BEK, Klein R, Nondahl DM. The association between cardiovascular disease and cochlear function in older adults. J. Speech Lang Hear. Res. 48(2):473-481, 2005.

VAn CAMP G, Sмith RJH. The hereditary hearing loss homepage. Accessed 2008, available at http://webh01.au.ac.be/hhh/.

Van Laer L, Van Eyken E, Fransen E, Huyghe JR, et al. The grainyheadlike 2 gene (GRHL2), alias TFCP2L3, is associated with age-related hearing impairment. Hum. Mol. Genet. 17:159-169, 2008.

Yu Z, Nissinen A, Vartiainen E, Song G, Guo Z, Zheng G, Tuomilehto J, Tian $H$. Changes in cardiovascular risk factors in different socioeconomic groups: seven year trends in a Chinese urban population. J. Epidemiol. Community Health. 54:692-696, 2000.

Yueh B, Shapiro N, Maclean CH, Shekelle PG. Screening and management of adult hearing loss in primary care: scientific review. JAMA. 289(15):1976-1985, 2003.

ZWAARDEMAKER H. Der verlust am hohen tonem mit zunehmendem alter. ein neues gesetz. Arch. f Ohrenh. 47, 1899. 